\title{
The Societal Economic Impact of Secukinumab in First-Line Treatment of Moderate to Severe Plaque Psoriasis in Germany: An Open-Cohort Simulation
}

\author{
Ahmed H. Seddik ${ }^{1}\left[\right.$ Nima Melzer $^{2} \cdot$ Foteini Tsotra $^{3} \cdot$ Dennis A. Ostwald ${ }^{3,4}$
}

Accepted: 16 September 2021 / Published online: 19 October 2021

(c) The Author(s) 2021

\begin{abstract}
Objectives Moderate to severe plaque psoriasis is a chronic inflammatory disease. In Germany, guidelines recommend fumaric acid esters (FAEs) as first-line systemic treatment. Despite treatment with FAEs, disease burden remains high in Germany. Secukinumab, a fully human monoclonal antibody, has demonstrated greater efficacy and safety than FAEs in the PRIME trial. The aim of the current study, hence, is to quantify the potential societal economic impact of secukinumab in systemic treatment-naïve patients with moderate to severe plaque psoriasis in Germany.

Methods We employed a semi-Markov model to capture health gains at an individual level and a dynamic population model to extrapolate the findings in the population of interest. We quantified the health outcomes in two scenarios: (i) patients receiving secukinumab and (ii) patients receiving FAEs. Using estimates on change in work productivity and societal economic parameters, we translated the health outcomes into paid and unpaid economic gains. We used gross value added (GVA) to value these gains and calculated the macroeconomic indirect and induced value-chain effects.

Results Our calculations show that patients treated with secukinumab spend on average $94 \%$ of their time in Psoriasis Area and Severity Index (PASI) $\geq 75$ state compared with $80 \%$ for patients in the FAEs scenario. When assuming that FAEs are the sole comparator to secukinumab, this difference could lead to 4.3 million active hours gained until 2030. These gained hours translate to a total societal economic impact of $€ 308$ million till 2030 for the whole patient population in GVA terms. Conclusion This study demonstrated that using secukinumab instead of FAEs in moderate to severe plaque psoriasis could lead to substantial macroeconomic GVA gains.
\end{abstract}

\section{Key Points for Decision Makers}

The potential societal economic impact of secukinumab for systemic treatment-naïve patients with moderate to severe plaque psoriasis in Germany could amount to $€ 308$ million till 2030.

This figure incorporates novel macroeconomic aspects that capture and monetize the societal economic impacts of a health innovation beyond what is conventionally measured in standard economic evaluations.

Ahmed H. Seddik

ahmed.seddik@daiichi-sankyo.eu

Daiichi-Sankyo Europe GmbH, Munich, Germany

Novartis Pharma GmbH, Nuremberg, Germany

3 WifOR Institute, Darmstadt, Germany

4 SIBE, Graduate School of the Faculty for Leadership and Management, Steinbeis University, Berlin, Germany

\section{Introduction}

Psoriasis is a chronic, painful, non-communicable disease $[1,2]$. In Germany, it is a frequent chronic inflammatory disease with reported 1-year prevalence of $2.5 \%$; among those, $25 \%$ have moderate to severe forms [3]. Numerous clinical phenotypes of psoriasis exist, including plaque psoriasis, guttate psoriasis, pustular psoriasis, erythrodermic psoriasis and nail psoriasis [4]. Chronic plaque psoriasis (psoriasis vulgaris), the most common type, accounts for $90 \%$ of all cases [5]. It may appear at any age but it is most prevalent in adults 55-75 years old [6]. There are conflicting reports about the gender distribution of the disease; however, in Germany the disease prevalence in women is estimated to be slightly higher than men [7].

The main clinical sign of plaque psoriasis is the presence of raised, red and scaly plaques. Often, these plaques are itchy and painful [8]. Classification of the severity of the disease involves the extent of body surface affected and the morphologic evaluation [9]. The diagnosis of the 
disease is based on clinical examination [9]. The Psoriasis Area and Severity Index (PASI) is the most common severity measurement tool, which scores affected parts and clinical appearance of psoriatic lesions [10].

Even though psoriasis is not a life-threatening disease, it is associated with clinical and emotional morbidity and has a significant impact on patients' quality of life. The quality of life decreases as the severity of symptoms increases [2]. Psoriasis affects patients' relationships and everyday life as they are frequently stigmatized, especially when visible skin is affected [5]. The disease is associated with physical burden as a result of the pain and itching and psychosocial burden caused by stigmatization and the chronic nature of the disease [3]. The disease primarily involves the skin, but it is difficult to project the progression of the disease.

Treatment approaches are usually individualized based on the clinical picture, patients' expectations, responses and adherence, co-morbidities and the risk of complications [11]. Current recommendations suggest topical therapy in mild cases [12]. In moderate to severe cases, initiating treatment with phototherapy (UVB, light and bath PUVA) and conventional systemic therapy (methotrexate, acitretin, cyclosporine, fumaric acid esters [FAEs]) is indicated. In the case of insufficient treatment response, intolerance or contraindication, physicians are recommended to switch to biologic agents. After some biologic therapies were approved for first-line use, guidelines have been adapted to recommend first-line use of biologics in patients for whom conventional systemic treatment will likely not be sufficient [12]. In Germany, FAEs are among the most common first-line systemic treatments. However, in other European countries, methotrexate is the standard first-line treatment [13]. FAEs are associated with a high rate of adverse events such as gastrointestinal disorders [13].

The use of traditional therapies (topical therapy, phototherapy, conventional systemic therapy) poses challenges to treatment adherence and clinical responsiveness, as they often correlate with poor patient satisfaction and adverse events [14]. In a meta-analysis, more patients treated with biological medicines achieved an improvement of at least $90 \%$ in their PASI score (PASI $\geq 90$ response). Such biologic treatments are considered to be the most effective systemic treatment options for psoriasis [15].

Secukinumab is a fully human monoclonal antibody that intentionally neutralizes IL-17A [16], a cornerstone cytokine involved in the development of psoriasis [17]. In clinical trials, secukinumab has shown long-lasting efficacy and safety in the complete spectrum of psoriasis manifestations, including nails, scalp, palms and soles and psoriatic arthritis [18-21]. In 2015, secukinumab was granted a marketing authorization in the European Union for the treatment of moderate to severe plaque psoriasis in adults who are candidates for systemic therapy [22]. It is the first biological treatment that has been approved as the first-line systemic treatment of moderate to severe plaque psoriasis in Europe [23].

An RCT conducted in Germany, the PRIME trial, compared secukinumab to FAEs in systemic treatment-naïve patients with moderate-to-severe plaque psoriasis. The results indicated that secukinumab had higher efficacy in PASI 75, 90 and 100 responses $(\geq 75 \%, \geq 90 \%$ and $100 \%$ improvement in PASI, respectively). In addition, secukinumab-treated patients also reported higher improvement in quality of life. Furthermore, treatment with FAEs was associated with more side effects and greater discontinuation rates [23].

The aim of this study was to assess the extent by which first-line treatment with secukinumab could reduce the societal economic burden associated with moderate to severe plaque psoriasis. With approval of biologics for first-line use, it might be unclear whether replacing conventional treatments yields economic benefit to the society paying for the innovation. Hence, the purpose of our study was to estimate the possible productivity gains related to an innovative biologic compared with conventional therapy in Germany. We used direct head-to-head data available for secukinumab and FAEs and took a societal perspective for Germany to estimate the economic impact of this paradigm shift in treatment prescription.

\section{Methods}

The starting point of our analysis was through calculating the number of patient-years spent in the PASI $\geq 75$ responder state. PASI score is widely adopted for informing clinical decisions in plaque psoriasis treatment and is one of the main scores used in the S3 Guideline for the treatment of psoriasis vulgaris [12]. PASI $\geq 75$ state was chosen as it has shown to correlate with improved work productivity for patients [24]. The objective of the statistical model was, therefore, to quantify the number of PASI $\geq 75$ patient-years in two scenarios: Scenario I where the patients receive secukinumab as first-line treatment, and an alternative scenario (Scenario II) where the same patient population receives FAEs in first line. In both scenarios, the patients were assumed to receive adalimumab as second-line treatment (Fig. 1). The incremental difference between the first scenario and the second scenario constitutes the calculated health gains and societal economic impact of using secukinumab as a firstline treatment. The model's time horizon was set to cover 2016-2030. This was chosen as it encompasses the time since authorization and early access in Germany and is 
long enough to capture the long-term impact expected by wider adoption of the innovation.

The model consisted of the following elements: a survival analysis model to quantify the health outcomes on the individual level, a population model to extrapolate the health outcomes amongst the entire population in question, and a societal economic model to value the health outcomes in monetary terms. The model simulation started in the year 2016 with a time horizon of 14 years until 2030 and had cycles of 1 year each. We describe those elements in further detail below.

\subsection{Individual-Level Simulation}

The simulation was based on survival analysis to depict the events of patients discontinuing treatment due to adverse events while on first-line treatment, as well as the event of death according to the age-specific all-cause mortality. Additionally, the probability of being a PASI $\geq 75$ responder given the respective treatment each year was applied. We therefore assumed that patients remained on first-line treatment (i.e. secukinumab in Scenario I and FAEs in Scenario II) as long as they are (i) PASI $\geq 75$ responders, (ii) not having an adverse event that leads to discontinuation of treatment and (iii) alive according to the age-specific mortality rates (Fig. 2).

To derive the annual PASI $\geq 75$ response rates and the rates of adverse events leading to discontinuation, we used data from clinical trials. The background mortality throughout time for the different age groups was derived from the German life tables [25]. Deriving annual probabilities on first-line treatment discontinuation due to an adverse event was based on parametrization of Kaplan-Meier models of the PRIME study [26] (Fig. S1, see electronic supplementary material [ESM]). When selecting the best-fitting parametric model amongst the adverse event survival curves, we considered the clinical plausibility of each model as well as their statistical performance and we visually assessed them for goodness of fit to the Kaplan-Meier curve. For the secukinumab survival models, we selected the exponential model since it assumes constant hazard throughout time and hence produced the most conservative survival estimates by assuming fewer patients remain on secukinumab in the longer term (Fig. S2, see ESM).

While all FAEs models were visually well fitting to the Kaplan-Meier data, we selected the log-normal curve since it had the smallest Akaike's Information Criterion (AIC) and Bayesian Information Criterion (BIC) values (Table S1, see ESM). The log-normal curve also presented the most conservative scenario since it assumed that patients remained on FAEs treatment for the longest time compared with the other parametric models (Fig. S3, see ESM).

The survival function of having an adverse event leading to discontinuation for each time point based on the selected parametric model for each scenario was multiplied by the overall survival probability at the same time point to calculate a compound probability for being alive and not having an adverse event leading to discontinuation at the same time. Additionally, this compound probability was multiplied by the annual probability of maintaining PASI $\geq 75$ response based on clinical trial data. Data on first-year PASI $\geq 75$ response rate of secukinumab and FAEs as first-line treatment were derived from the head-to-head PRIME study [26]. While it was conservatively assumed that FAEs' response does not decrease over time, a lower long-term response rate of secukinumab was derived from the SCULPTURE study [27] and applied for the second year onwards.

When patients switch to second-line treatment, they were assumed to receive adalimumab until the end of the time horizon of the analysis or until an event of death occurs. We assumed that patients on adalimumab show average PASI $\geq 75$ response rates every year as reported by the long
Fig. 1 The model structure for the two hypothetical scenarios. FAEs fumeric acid esters
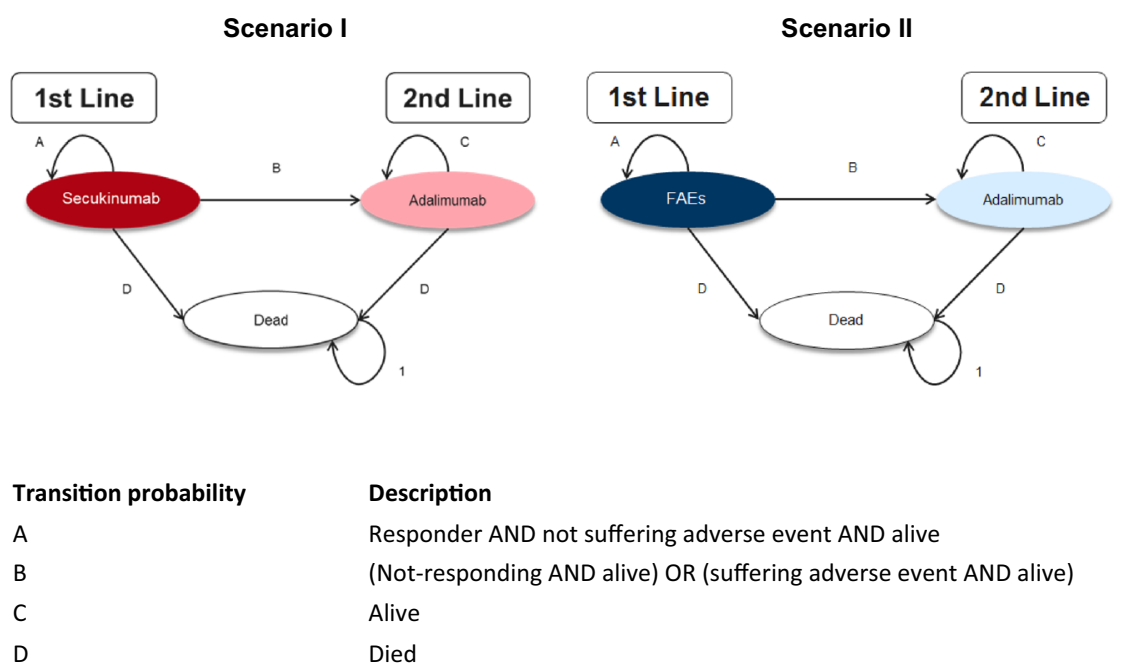
Fig. 2 Schematic representation of the events occurring during one cycle of the model. $A E$ adverse event, PASI Psoriasis Area and Severity Index

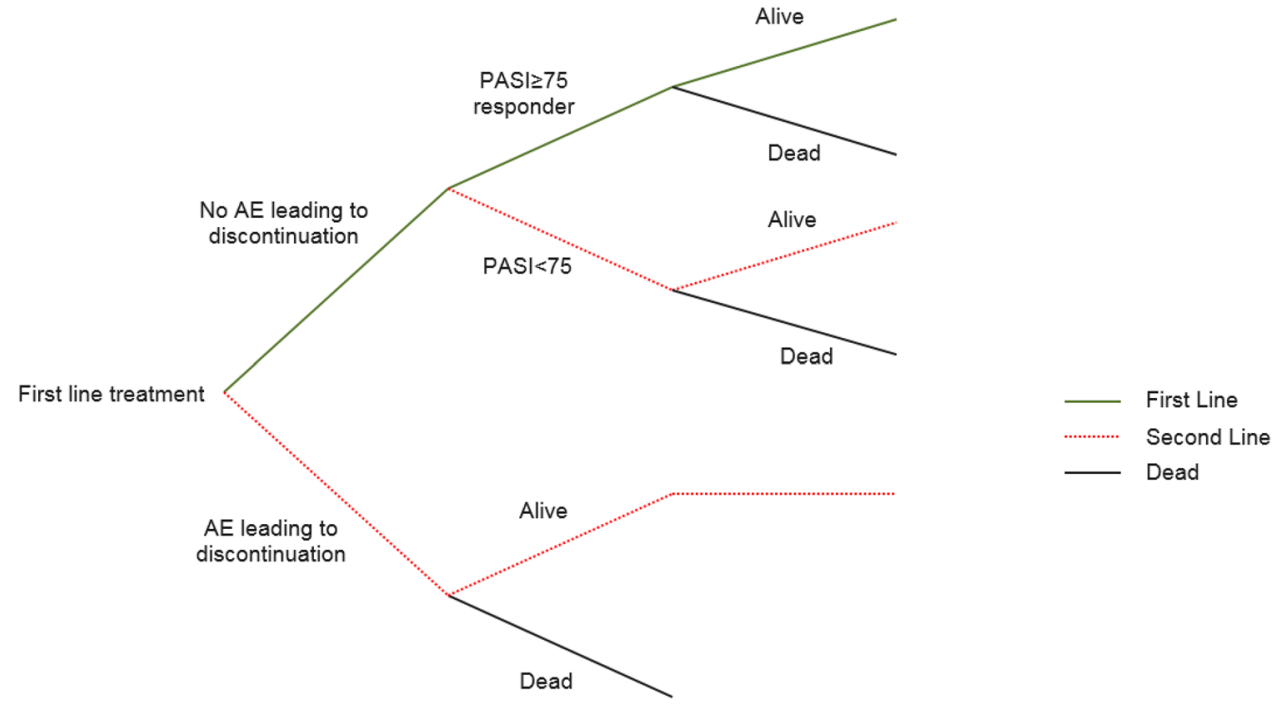

term REVEAL study [28] (Table S2, see ESM). This is a simplification of the real-life situation where patients might also discontinue adalimumab treatment for different reasons (e.g. loss of response or adverse events) and proceed to later therapy lines. However, this assumption was the most conservative and parsimonious since the incremental benefit in our model is calculated as the difference in PASI $\geq 75$ person-years between scenarios I and II, and both scenarios included the possibility of a second-line treatment with adalimumab. Under this assumption for second-line treatment, patients who stay for a relatively longer duration in first-line with secukinumab are compared against adalimumab as a second-line option, which is a biologic treatment with relatively high efficacy. Figure 3 depicts the results of the individual-level simulation, where the assumptions on adverse event rates per treatment arm, together with assumptions on PASI $\geq 75$ response rates, result in different time on first-line treatment in the two modelled scenarios.

The described modelling was applied to six age groups that varied by the selected array representing the age-specific and time-dependant background mortality; those were
$20-29,30-39,40-49,50-59,60-69$ and $70+$ years. This subgrouping was selected due to its relevance to the societal economic valuation of the time spent in PASI $\geq 75$, described in detail in Sect. 2.3.

\subsection{Population Model}

We built a dynamic population model to simulate the health effects among the patient population projected to receive secukinumab over time, that is, systemic treatment-naïve patients with moderate to severe plaque psoriasis receiving secukinumab according to market share forecasts.

To estimate the cohort sizes of new patients starting secukinumab for the indication in question every year, we used real-world data on file for the years 2016-2019 and fitted and extrapolated them using a logarithmic function to the year 2025 [29]. From year 2025 until 2030 we assumed a constant number of patients starting secukinumab treatment every year (Fig. S4, see ESM).
Fig. 3 14-year modelling of the average patient in the age group 50-59 for scenarios I and II. FAEs fumeric acid esters

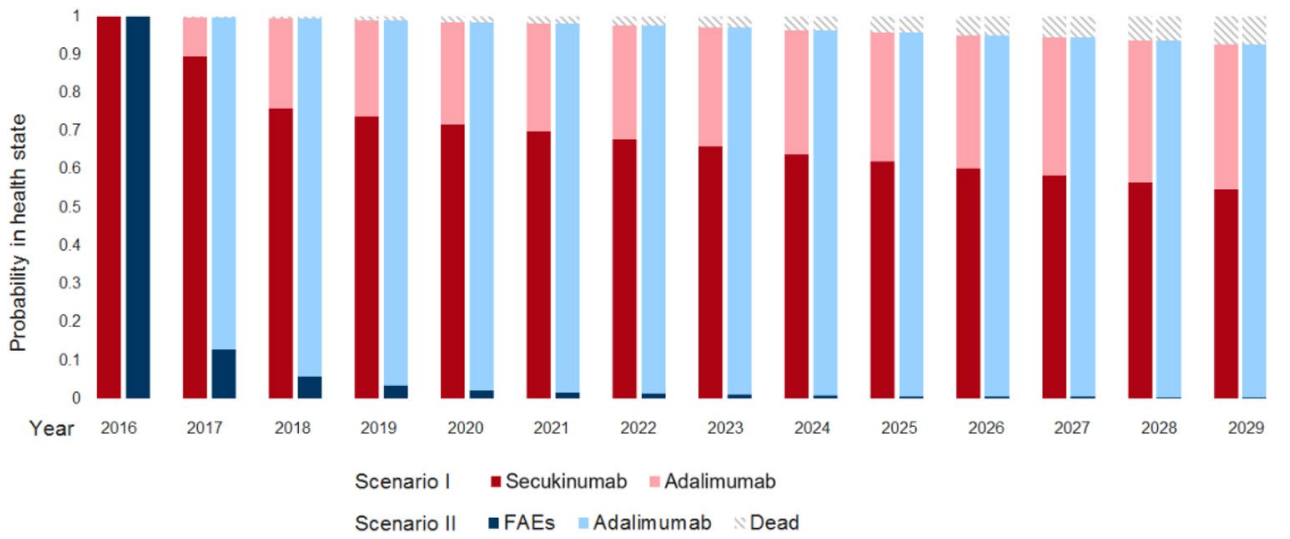


Furthermore, we applied epidemiological evidence to estimate the relative sizes of the patient cohorts in the predefined age subgroups. The estimates used to depict the age distribution of the incidence cohorts of plaque psoriasis were derived from the study by Huerta et al. [30].

In this way, and as specified in the previous section on the individual-level simulation, the time patients spent on secukinumab and FAEs treatments was assumed to be equivalent to time in a PASI $\geq 75$ state, while $76 \%$ of the time spent on adalimumab was equivalent to time in PASI $\geq 75$ [28]. Therefore, PASI $\geq 75$ person-years were accrued for each cohort and treatment scenario for the time horizon of the model. In a last step, PASI $\geq 75$ patient-years gained were divided for male and female cohorts based on the estimates from the German reimbursement value dossier [31]. All inputs used for quantifying the health gains can be found in Table S2 (see ESM).

\subsection{Societal Economic Valuation of PASI $\geq 75$ Patient-Years}

The time spent in PASI $\geq 75$ is expected to be associated with decreased paid and unpaid work absenteeism and presenteeism. This association was reported in a study by Kimball and colleagues [32]. In this study, the authors report the estimated change in work productivity after 16 weeks of PASI $\geq 75$ response using Work Productivity and Activity Impairment Questionnaire for Psoriasis (WPAI-Psoriasis) and its correlation with PASI $\geq 75$ response at baseline and after 16 weeks using data from the REVEAL study.

Applying the estimates from Kimball et al. and using key societal economic figures from official statistics and other sources, the number of paid hours gained were calculated using the following formula:

$H_{\mathrm{agj}}^{P}=\sum_{t=1}^{14} \alpha_{\mathrm{ag}} \times \beta_{\mathrm{ag}} \times \gamma_{\mathrm{ag} j} \times \delta_{j} \times \varepsilon_{\mathrm{ag}} \times \lambda$,

where $H_{\mathrm{agj}}^{P}$ are the age, gender and industry sector-specific total hours of paid work gained throughout the 14 cycles of the model. Table presents the definitions of the formula's parameters and subscripts.

\begin{tabular}{ll}
\hline Parameters & Gains in PASI $\geq 75$ patient-years \\
$\alpha$ & Employment rate \\
$\beta$ & Proportion of employees in each \\
$\gamma$ & industry sector \\
$\delta$ & Average number of daily working \\
& hours per year \\
$\varepsilon$ & Age and gender working hour \\
& multiplier \\
\hline
\end{tabular}

\begin{tabular}{ll}
\hline$\lambda$ & $\begin{array}{c}\text { \% Difference to baseline in Total } \\
\text { Work Productivity Impairment } \\
\text { for PASI }>75 \text { responders after } \\
16 \text { weeks }\end{array}$ \\
Subscripts & Age \\
$a$ & Gender \\
$j$ & Industry sector \\
$t$ & Time (model cycle) \\
\hline
\end{tabular}

PASI Psoriasis Area and Severity Index

${ }^{a}$ National account data do not report working hours stratified by age and gender, but working hours differ across gender and age groups. Therefore, we calculated age- and gender-specific working hour multipliers based on data from the German Institute for Employment Research (IAB) [33]

For quantifying hours of unpaid work gained, the equation and parameters below were used:

$H_{\mathrm{ag} j}^{U}=\sum_{t=1}^{14} \alpha_{\mathrm{ag}} \times \theta_{\mathrm{ag} j} \times \mu$,

where $H_{a g j}^{U}$ is the age, gender and unpaid activity-specific total number of hours of unpaid work gained throughout the 14 cycles of the model. Table presents the definitions of the formula's parameters and subscripts.

\begin{tabular}{ll}
\hline Parameters & \\
$\alpha$ & PASI $\geq 75$ patient-years \\
$\theta$ & Hours spent on unpaid work \\
& activities per year \\
$\mu$ & \% Difference to baseline in Total \\
& Activity Impairment for PASI $\geq$ \\
& 75 responders after 16 weeks \\
Subscripts & \\
$a$ & Age \\
$g$ & Gender \\
$j$ & Unpaid activity \\
$t$ & Time (model cycle) \\
\hline
\end{tabular}

PASI Psoriasis Area and Severity Index

The accrued hours of paid work gained were valued by multiplying them to the industry-specific average gross value added (GVA) per hour in the year 2017 [34]. The unpaid activities were first mapped to their nearest market substitute in the industry; the unpaid hours were then valued according to the mapped industry-specific average GVA per hour. This so-called specialist approach in valuing unpaid work has been described in detail in the work of Hofmann [35]. The outcomes of those calculations make up the direct gains in GVA due to increased patient productivity.

Furthermore, we calculated the estimated value-chain effects in the economy that are expected to arise as a result of the increased economic activity of a healthier patient 
population. The value-chain effects were calculated using Leontief multipliers [36], which were derived from the German input-output tables using an input-output model [37].

Indirect effects are effects arising due to the input an industry demands from other economic agents. Order placements result in an increase of economic activity at commissioned agents and their suppliers. This stimulus increases GVA and other key economic figures along the supply chain. Induced effects originate from the expenditure of directly and indirectly generated incomes and the concomitant increase in demand. The combination of indirect and induced effects is called spill-over or value-chain effects. The total societal economic impact in this study refers to the sum of all three direct, indirect and induced effects [38].

All input parameters used in the societal economic valuation of the health gains are listed in detail in Table S3 (see ESM).

\subsection{Sensitivity Analysis}

To test the model for robustness and explore the parameters towards which the model is most sensitive, we conducted sensitivity analyses. A one-way deterministic sensitivity analysis was conducted to explore the parameters with highest influence on the model's outcome reported as the accumulative societal economic impact until 2030. Additionally, probabilistic sensitivity analysis was conducted to explore the effect of parameter uncertainty on the model's outcome. The sensitivity analyses included the clinical and epidemiological inputs used to simulate the health outcomes of the model and estimates on upper and lower bounds were derived from $95 \%$ confidence intervals whenever applicable. As all societal economic inputs were derived directly from population data, no statistical uncertainty was associated with them and hence they were not included in the sensitivity analysis. Since we assumed that age-specific employment rates among patients with psoriasis correspond to those of the total population, we tested the parameters we used on employment rate by varying them $\pm 20 \%$ while assuming normal distribution around the mean base-case value. Assumptions on statistical distributions were made depending on the parameter type. All parameters and distributions used in the sensitivity analysis are listed in Table S5 (see ESM).

The described model has been built using Excel 365 and Visual Basic for Applications.

\section{Results}

Until the year 2030 in Germany, the estimated annual average number of patients on secukinumab for first-line systemic treatment of plaque psoriasis in Scenario I is estimated to be 4394, while the average number of patients on FAEs in Scenario II is estimated at 921. After implementing the clinical inputs on the PASI $\geq 75$ response rates for the treatment options considered (secukinumab and adalimumab for Scenario I, and FAEs and adalimumab for Scenario II), it is estimated that an average patient in Scenario I would spend $94 \%$ of their time in the PASI $\geq 75$ state, while the average patient in Scenario II would spend $80 \%$ of their time in the same state (Fig. 4).

In this way and until the year 2030, the total aggregate gains in PASI $\geq 75$ patient-years across all age groups was estimated at 11,669. This translates into a total of 4.3 million active hours gained until year $2030,71 \%$ of which are gains in unpaid working time (Fig. 5).

When valuing the gains in active time for potential GVA effects by industry sector, the average annual societal economic impact per patient is estimated at $€ 3495$. The total societal economic impact of secukinumab for the whole patient population adds up to a cumulative total of $€ 308$ million until 2030, with an annual average of $€ 22.0$ million. Of those gains, $49 \%$ are attributable to direct effects and $51 \%$ to indirect and induced value-chain effects (Table 1).

\subsection{Sensitivity Analysis}

The results of the one-way deterministic sensitivity analysis show that the model's outcome reported as the cumulative societal economic impact over 14 years is robust to variation of the main model's parameters. The input parameters against which the model is most sensitive are those pertaining to market share estimates of secukinumab (prevalence and incidence populations) when varying them $\pm 20 \%$ off the base-case estimates.

The model has shown to be robust when running a Monte Carlo simulation in which model parameters were simultaneously varied according to random draws from prespecified statistical distributions. The mean societal economic impact after 10,000 model iterations was found to be $€ 307.8$ million ( $\mathrm{SD} \pm 36.8$ million), Fig. 6 .

\section{Discussion}

This study shows the societal economic impact of the use of secukinumab in systemic therapy-naïve patients with moderate to severe psoriasis in Germany. The cumulative impact from a macroeconomic perspective is estimated at $€ 308$ million, with an average of $€ 3495$ per patient per year. The study builds on a methodology that includes novel elements to health economic evaluations, which are monetary gains in unpaid work as well as potential economic downstream value-chain effects. Those elements, as also shown by two other studies with similar methodology [39, 40], 


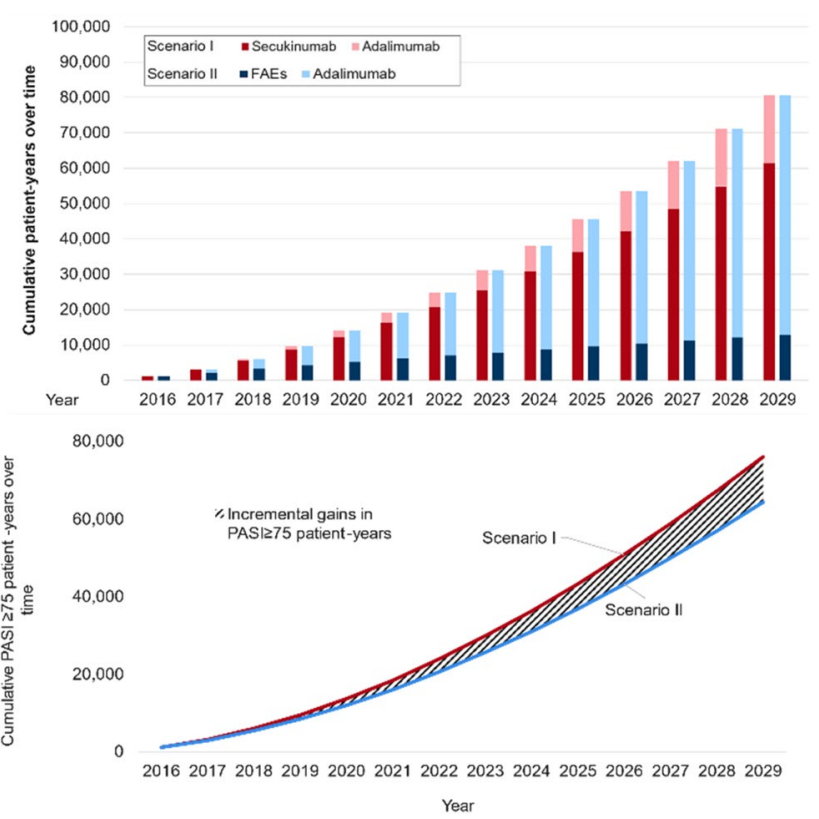

Fig. 4 Results of the health model until year 2030. FAEs fumeric acid esters, PASI Psoriasis Area and Severity Index

\section{Cumulative active hours gained in 14 years}

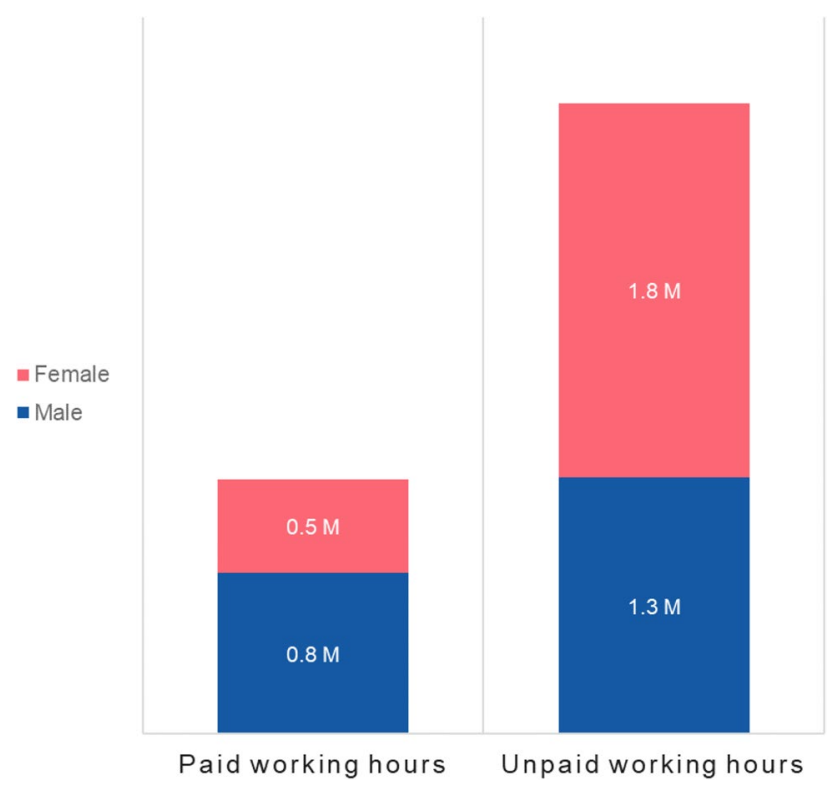

Fig. 5 Cumulative societal economic gains until year 2030, calculated as the difference in GVA between the secukinumab and FAEs scenarios. FAEs fumeric acid esters, $M$ million, GVA gross value added

highlight the value brought about by innovative medicines that otherwise go unmeasured and unvalued in conventional cost-effectiveness and budget impact analyses. In our study,
Table 1 Average societal economic impact of first-line systemic use of secukinumab in plaque psoriasis in Germany in 1 year (total population and per patient). Calculated as the difference in total gross value added between the secukinumab scenario and the FAEs scenario

\begin{tabular}{lll}
\hline & \multicolumn{2}{l}{$\begin{array}{l}\text { Monetary valuation }(€) \text { of hours } \\
\text { gained due to secukinumab in terms } \\
\text { of GVA (average per patient) }\end{array}$} \\
\cline { 2 - 3 } & Paid work & Unpaid work \\
\hline Direct effect $^{\mathrm{a}}$ & $4.2 \mathrm{M} \mathrm{(668)}$ & $6.6 \mathrm{M} \mathrm{(1046)}$ \\
Indirect effect $^{\mathrm{b}}$ & $3.0 \mathrm{M} \mathrm{(477)}$ & $3.8 \mathrm{M}(610)$ \\
Induced effect $^{\mathrm{c}}$ & $1.9 \mathrm{M} \mathrm{(296)}$ & $2.5 \mathrm{M}(399)$ \\
Total (social impact) & $9.1 \mathrm{M} \mathrm{(1440)}$ & $12.9 \mathrm{M}(2055)$ \\
\hline
\end{tabular}

FAEs fumaric acid esters, GVA gross value added, $M$ million

${ }^{\text {a }}$ Direct effect: refers to the monetary valuation of working time in terms of gross value added per working hour

${ }^{b}$ Indirect effect: economic effects due to the intermediate consumption of goods and services from suppliers associated with a change in direct gross value added

${ }^{\mathrm{c}}$ Induced effect: economic effects originating from household spending of income generated by direct and indirect economic effects

unpaid work activities make up 59\% of the potential societal economic impact, while $51 \%$ of the estimated impact is related to value-chain effects due to a healthier and more productive patient population.

Psoriasis is accompanied by a high societal economic burden globally. Internationally, annual mean costs for psoriasis vary between $€ 1079$ to $€ 11,928$ per patient [41]. It also negatively affects a patients' employment and leisure time activities [42]. Work presenteeism and absenteeism are often reported as the most significant reasons for productivity loss. Berger et al. [43] estimated that patients with chronic plaque psoriasis in Germany have been absent from their work for approximately 49 days per year. Presenteeism is estimated to contribute around half of the indirect costs in psoriasis patients.

This is the first study to value the societal economic impact of secukinumab as a first-line treatment in systemic therapy-naïve patients with moderate to severe plaque psoriasis. Analyses of the economic burden of psoriasis in Germany have been conducted considering both direct and indirect costs. The study of Jungen et al. [41] has shown that the total annual cost of plaque psoriasis in Germany is about $€ 5543$ per patient, and the annual mean direct and indirect costs per patient amount to $€ 5164$ and $€ 379$, respectively. Indirect costs measured in the referred study were defined as costs of absence days of work due to psoriasis. The findings of Jungen et al. [41] on the total annual cost of plaque psoriasis ( $€ 5543$ per patient) compared with our estimates ( $€ 3495$ average annual societal economic impact per patient) indicate the potentially significant societal economic impact of secukinumab. In a primary analysis conducted in the UK, 

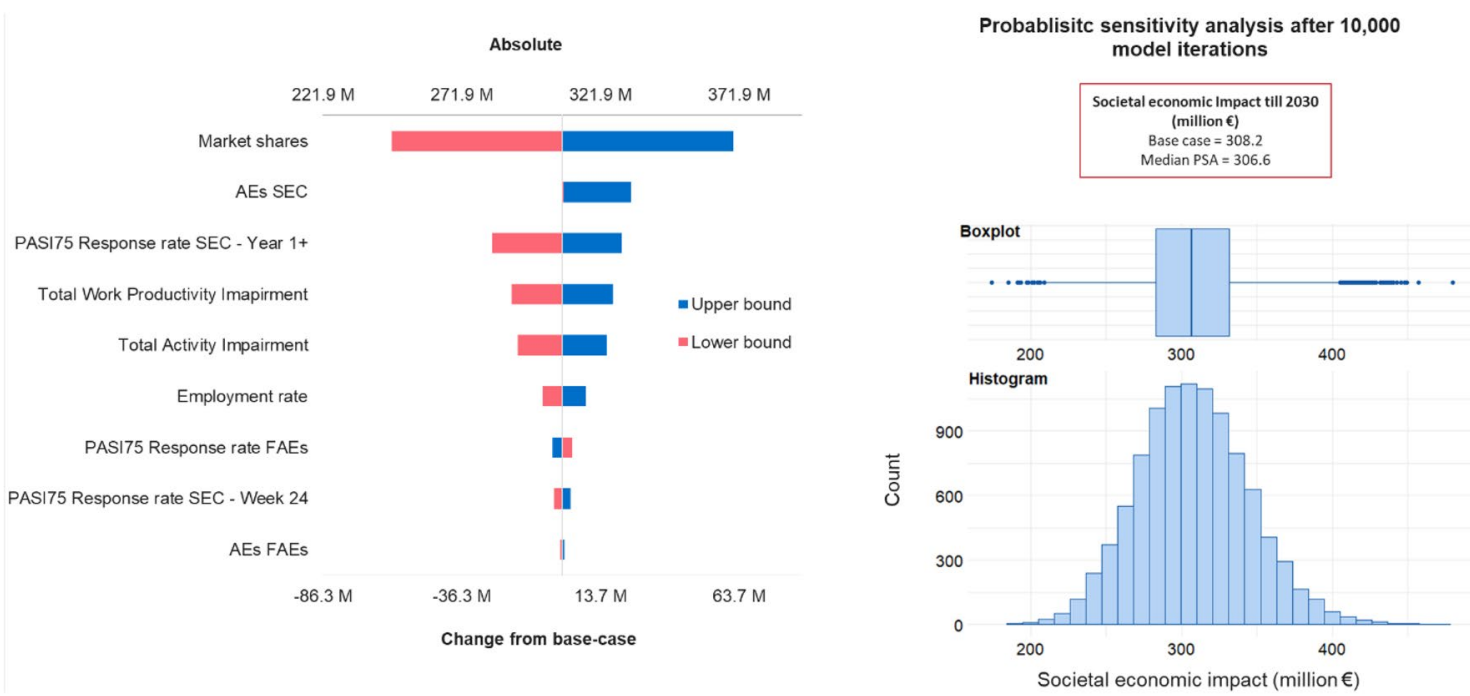

Fig. 6 Results of the sensitivity analysis (cumulative societal economic impact until year 2030). AEs adverse events, FAEs fumeric acid esters, $M$ million, PASI Psoriasis Area Severity Index, SEC: secukinumab, PSA probabilistic sensitivity analysis

the average weekly/annual work hours lost due to psoriasis in patients receiving secukinumab were considerably lower than for those receiving ustekinumab, and the indirect cost savings were estimated to be $\mathfrak{3 5 6}$ per patient. In a secondary analysis, compared with etanercept, the annual workrelated indirect cost savings associated with secukinumab were $£ 1017$. In both cases, the indirect costs were calculated as the product of work productivity loss and the hourly wage data [24]. In an Italian study [44], the reduction of working capacity before the initiation of biologic treatment for chronic plaque psoriasis was 18.0 days per year, which reduced to 4.9 days with biologics. This translated to a $73 \%$ reduction in lost work capacity, which shows that our results comply with already existing evidence and that our approach yields realistic evaluations.

\subsection{Assumptions and Limitations}

While this study builds on solid clinical and societal economic data to present novel results as a means of extending the possible dimensions in assessing the value of an innovative therapy, our methodology was built on several assumptions and had its limitations. First, it was assumed that FAEs would have been (and would remain until 2030) the systemic first-line treatment for patients with moderate to severe plaque psoriasis, unless replaced by secukinumab. This assumption was limited by the availability of clinical data for the population in question. At the time the study was conducted, secukinumab was the only biologic approved for first-line therapy. For that reason, FAEs were the most suitable first-line comparator and for which sufficient data for comparison were available. Additionally, it was assumed that patients on second-line treatment receive adalimumab and remain on treatment if they are alive. This assumption was the most parsimonious and conservative as described in the methods section. Adalimumab was selected as it was the most efficacious biologic treatment authorized in Germany for systemic treatment of plaque psoriasis and for which sufficient long-term evidence to run the analysis was available by the time this study was conducted. Furthermore, it was assumed that patients discontinue first-line treatment as soon as their PASI response score falls below 75 or as soon as they have an adverse event leading to discontinuation. It was also assumed that the probabilities of the three different events of (i) loss of PASI $\geq 75$ response, (ii) adverse events leading to discontinuation and (iii) death due to all-cause mortality are non-conditional (i.e. they are independent from one another); hence, it was assumed that the product of the three probabilities gives the probability of all three events occurring at once. While parameter uncertainty was examined in the reported sensitivity analyses, the previous assumptions related to quantifying the health outcomes of the model were bound by the availability of pertinent data and could have led to structural model uncertainty. It is worthwhile noting that parametric survival modelling was conducted to inform long-term extrapolations of the adverse event rates in both arms. Even when not the best-fitting visually and statistically, the exponential curve was selected for secukinumab as it presented the most conservative longterm extrapolation (assuming highest drop-out over time), while the log-normal curve was selected for FAEs based on lowest AIC and BIC. The numbers of patients receiving secukinumab between 2016 and 2018 were based on actual market share figures. An exploration of the trends in those 
real-world figures of patients on treatment lies outside the scope of this paper.

When translating the health outcomes to societal economic figures, the first step was to use estimates from the study from Kimball et al. to calculate the number of hours gained for PAS $\geq \mathrm{I} 75$ responder patients [32]. To monetize the gains in active paid and unpaid working hours, we used the approach that was similarly implemented by Himmler et al. The assumptions and limitations associated with this methodology (especially including unpaid activities and value-chain effects) were reported in detail in the referred studies [39, 40]. Additionally, while other more conservative approaches in valuing productive time exist (e.g. frictional cost method), the modified human capital approach that we implemented (applying GVA per working hour instead of wages) has been also frequently used in the psoriasis setting $[45,46]$. While the authors have explored the possibility of running a scenario analysis with PASI $\geq 90$ as the endpoint of interest, there was insufficient evidence to inform the translation of health outcomes to productivity gains for that endpoint. It is hence difficult to ascertain the direction in which the results of the study would have moved upon using PASI $\geq 90$ as the study endpoint.

Finally, this study builds on known present societal economic inputs and evaluates future projected outcomes based on those present values. In this way, our aim was not to build a dynamic simulation of the economy of Germany and explore how it develops throughout time, but rather to monetize the simulated health gains due to the use of an innovative medicine in the patient population. This is intended to aid decision makers when allocating budgets on high impact areas those innovations could potentially have upon the society.

\section{Conclusion}

Plaque psoriasis is a disease that is associated with significant health-related and financial burdens as shown by other studies. Evidence has shown that secukinumab is effective and safe compared with FAEs, which are considered the standard of care for first-line systemic treatment of patients with moderate to severe plaque psoriasis in Germany. This study quantified the health gains when the expected number of patients are treated with secukinumab until the year 2030. Those health gains translate, on average, into 0.31 million active hours gained each year. Those, in turn, are estimated to result in an average of $€ 22$ million of GVA annually.

In past years, criticism of health technology assessment (HTA) frameworks that were used to assess the value of innovation in healthcare was raised. In this study, we propose and implement an approach where we measure the societal economic impact of secukinumab from a macroeconomic perspective. This methodology generates evidence in a way that allows for engaging a broader range of stakeholders for a more inclusive HTA process. Presenting the estimated longterm impact of a health care innovation in monetary terms allows for a common denominator upon which health care decision makers as well as external stakeholders can evaluate and criticise clinical and patient-relevant outcomes. On this basis, rational decisions on resource allocation can be made while factoring comparable long-term consequences into the decision-making process.

Supplementary Information The online version contains supplementary material available at https://doi.org/10.1007/s41669-021-00305-3.

\section{Declarations}

Funding This study was funded by Novartis Pharma GmbH.

Conflict of interest Ahmed H. Seddik was an employee of WifOR institute by the time of completion of the study and writing the manuscript. Ahmed H. Seddik is currently an employee of Daiichi-Sankyo Europe. Foteini Tsotra is an employee of WifOR institute. Dennis A. Ostwald is the CEO of WifOR institute. Nima Melzer is an employee of Novartis. WifOR institute was commissioned by Novartis Pharma $\mathrm{GmbH}$ to conduct this study

Availability of data and material All relevant data for building the study model were reported in the body and annex of the manuscript

Code availability The model and analyses were developed in Excel 365 , VBA and R by WifOR institute and are proprietary property of Novartis Pharma GmbH

Authors' contributions Ahmed H. Seddik, Nima Melzer and Dennis A. Ostwald contributed to the design of the model. Ahmed H. Seddik, Nima Melzer and Foteini Tsotra contributed to the manuscript writing. All authors contributed to the interpretation of the data, revised the manuscript critically for important intellectual content and approved the final manuscript.

Ethics approval Not applicable.

Consent to participate No applicable.

Consent for publication Not applicable.

Open Access This article is licensed under a Creative Commons Attribution-NonCommercial 4.0 International License, which permits any non-commercial use, sharing, adaptation, distribution and reproduction in any medium or format, as long as you give appropriate credit to the original author(s) and the source, provide a link to the Creative Commons licence, and indicate if changes were made. The images or other third party material in this article are included in the article's Creative Commons licence, unless indicated otherwise in a credit line to the material. If material is not included in the article's Creative Commons licence and your intended use is not permitted by statutory regulation or exceeds the permitted use, you will need to obtain permission directly from the copyright holder. To view a copy of this licence, visit http://creativecommons.org/licenses/by-nc/4.0/. 


\section{References}

1. Michalek IM, Loring B, John SM. A systematic review of worldwide epidemiology of psoriasis. J Eur Acad Dermatol Venereol. 2017;31:205-12. https://doi.org/10.1111/jdv.13854.

2. World Health Organization. Global report on psoriasis. Geneva: World Health Organization; 2016. p. 5-19. https://apps.who.int/ iris/handle/10665/204417. Accessed 14 May 2020.

3. Augustin M, Eissing L, Langenbruch A, Enk A, Luger T, Maaßen D, Mrowietz U, Reich K, Reusch M, Strömer K, Thaçi D, von Kiedrowski R, Radtke MA. The German National Program on Psoriasis Health Care 2005-2015: results and experiences. Arch Dermatol Res. 2016;308:389-400. https://doi.org/10.1007/ s00403-016-1637-8.

4. Datta A, Mitr A. Clinical Presentation of Psoriasis. In: Lima H, editor. Psoriasis - types, causes and medication. Rijeka: InTech; 2013.

5. Schöffski O, Augustin M, Prinz J, Rauner K, Schubert E, Sohn $\mathrm{S}$, Reich K. Costs and quality of life in patients with moderate to severe plaque-type psoriasis in Germany: a multi-center study. JDDG. 2007;5:209-18. https://doi.org/10.1111/j.1610-0387.2007. 06240.x.

6. Augustin M, Reich K, Glaeske G, Schaefer I, Radtke M. Co-morbidity and age-related prevalence of psoriasis: analysis of health insurance data in Germany. Acta Derm Venereol. 2010;90:14751. https://doi.org/10.2340/00015555-0770.

7. Parisi R, Symmons DPM, Griffiths CEM, Ashcroft DM. Identification and Management of Psoriasis and Associated ComorbidiTy (IMPACT) project team: global epidemiology of psoriasis: a systematic review of incidence and prevalence. J Investig Dermatol. 2013;133:377-85. https://doi.org/10.1038/jid.2012.339.

8. Fala L. Cosentyx (Secukinumab): first IL-17A antagonist receives FDA approval for moderate-to-severe plaque psoriasis. Am Health Drug Benefits. 2016;9:60-3.

9. Raychaudhuri SK, Maverakis E, Raychaudhuri SP. Diagnosis and classification of psoriasis. Autoimmun Rev. 2014;13:490-5. https://doi.org/10.1016/j.autrev.2014.01.008.

10. Benezeder T, Wolf P. Resolution of plaque-type psoriasis: what is left behind (and reinitiates the disease). Semin Immunopathol. 2019;41:633-44. https://doi.org/10.1007/s00281-019-00766-z.

11. Medical Advisory Secretariat. Ultraviolet phototherapy management of moderate-to-severe plaque psoriasis: an evidence-based analysis. Ont Health Technol Assess Ser. 2009;9:1-66.

12. Nast A, Amelunxen L, Augustin M, Boehncke W, Dressler C, Gaskins M, Härle P, Hoffstadt B, Klaus J, Koza J, Mrowietz U, Ockenfels H, Philipp S, Reich K, Rosenbach T, Rzany B, Schlaeger M, Schmid-Ott G, Sebastian M, Kiedrowski R, Weberschock T. S3 Guideline for the treatment of psoriasis vulgaris, updateshort version part 1 - systemic treatment. J Dtsch Dermatol Ges. 2018;16:645-69. https://doi.org/10.1111/ddg.13516.

13. Mrowietz U, Barker J, Boehncke W-H, Iversen L, Kirby B, Naldi L, Reich K, Tanew A, van de Kerkhof PCM, Warren $\mathrm{RB}$. Clinical use of dimethyl fumarate in moderate-to-severe plaque-type psoriasis: a European expert consensus. J Eur Acad Dermatol Venereol. 2018;32:3-14. https://doi.org/10.1111/jdv. 15218.

14. Gisondi P, Del Giglio M, Girolomoni G. Treatment approaches to moderate to severe psoriasis. Int J Mol Sci. 2017;18(11):2427. https://doi.org/10.3390/ijms1811242715.

15. Sbidian E, Chaimani A, Afach S, Doney L, Dressler C, Hua C, Mazaud C, Phan C, Hughes C, Riddle D, Naldi L, Garcia-Doval I, Le Cleach L. Systemic pharmacological treatments for chronic plaque psoriasis: a network meta-analysis. Cochrane Database Syst Rev. 2020. https://doi.org/10.1002/14651858.CD011535. pub3.
16. Reich K, Blauvelt A, Armstrong A, Langley RG, de Vera A, Kolbinger F, Spindeldreher S, Ren M, Bruin G. Secukinumab, a fully human anti-interleukin-17A monoclonal antibody, exhibits low immunogenicity in psoriasis patients treated up to 5 years. J Eur Acad Dermatol Venereol. 2019;33:1733-41. https://doi.org/10. $1111 / j d v .15637$.

17. Zeichner JA, Armstrong A. The role of IL-17 in the pathogenesis and treatment of psoriasis. J Clin Aesthet Dermatol. 2016;9(6 Suppl 1):S3-6.

18. Langley RG, Elewski BE, Lebwohl M, Reich K, Griffiths CEM, Papp K, Puig L, Nakagawa H, Spelman L, Sigurgeirsson B, Rivas E, Tsai T-F, Wasel N, Tyring S, Salko T, Hampele I, Notter M, Karpov A, Helou S, Papavassilis C. ERASURE Study Group, FIXTURE Study Group: secukinumab in plaque psoriasisresults of two phase 3 trials. N Engl J Med. 2014;371:326-38. https://doi.org/10.1056/NEJMoa1314258.

19. Thaçi D, Blauvelt A, Reich K, Tsai T-F, Vanaclocha F, Kingo K, Ziv M, Pinter A, Hugot S, You R, Milutinovic M. Secukinumab is superior to ustekinumab in clearing skin of subjects with moderate to severe plaque psoriasis: CLEAR, a randomized controlled trial. J Am Acad Dermatol. 2015;73:400-9. https://doi.org/10.1016/j. jaad.2015.05.013.

20. McInnes IB, Mease PJ, Kirkham B, Kavanaugh A, Ritchlin CT, Rahman P, van der Heijde D, Landewé R, Conaghan PG, Gottlieb AB, Richards H, Pricop L, Ligozio G, Patekar M, Mpofu S. Secukinumab, a human anti-interleukin-17A monoclonal antibody, in patients with psoriatic arthritis (FUTURE 2): a randomised, double-blind, placebo-controlled, phase 3 trial. Lancet. 2015;386:1137-46. https://doi.org/10.1016/S0140-6736(15) 61134-5.

21. Baeten D, Baraliakos X, Braun J, Sieper J, Emery P, van der Heijde D, McInnes I, van Laar JM, Landewé R, Wordsworth P, Wollenhaupt J, Kellner H, Paramarta J, Wei J, Brachat A, Bek S, Laurent D, Li Y, Wang YA, Bertolino AP, Gsteiger S, Wright AM, Hueber W. Anti-interleukin-17A monoclonal antibody secukinumab in treatment of ankylosing spondylitis: a randomised, double-blind, placebo-controlled trial. Lancet. 2013;382:1705-13. https://doi.org/10.1016/S0140-6736(13)61134-4.

22. European Medicines Agency: Cosentyx: EPAR - product information. 2018. https://www.ema.europa.eu/en/documents/productinformation/cosentyx-epar-product-information_en.pdf. Accessed 14 May 2020.

23. Sticherling M, Mrowietz U, Augustin M, Thaçi D, Melzer N, Hentschke C, Kneidl J, Sieder C, Reich K. Secukinumab is superior to fumaric acid esters in treating patients with moderate-tosevere plaque psoriasis who are naive to systemic treatments: results from the randomized controlled PRIME trial. Br J Dermatol. 2017;177:1024-32. https://doi.org/10.1111/bjd.15707.

24. Warren RB, Halliday A, Graham CN, Gilloteau I, Miles L, McBride D. Secukinumab significantly reduces psoriasis-related work impairment and indirect costs compared with ustekinumab and etanercept in the United Kingdom. J Eur Acad Dermatol Venereol. 2018;32:2178-84. https://doi.org/10.1111/jdv.15094.

25. Statistisches Budesamt: Sterbetafel 2013/2015. https://www.desta tis.de/DE/Publikationen/Thematisch/Bevoelkerung/Bevoelkeru ngsbewegung/PeriodensterbetafelnBundeslaender.html. Accessed 14 May 2020.

26. Novartis: ad-hoc analysis of clinical data from the PRIME study (data on file).

27. Bissonnette R, Luger T, Thaçi D, Toth D, Lacombe A, Xia S, Mazur R, Patekar M, Charef P, Milutinovic M, Leonardi C, Mrowietz U. Secukinumab demonstrates high sustained efficacy and a favourable safety profile in patients with moderate-to-severe psoriasis through 5 years of treatment (SCULPTURE Extension Study). J Eur Acad Dermatol Venereol. 2018;32:1507-14. https:// doi.org/10.1111/jdv.14878. 
28. Gordon K, Papp K, Poulin Y, Gu Y, Rozzo S, Sasso EH. Longterm efficacy and safety of adalimumab in patients with moderate to severe psoriasis treated continuously over 3 years: Results from an open-label extension study for patients from REVEAL. J Am Acad Dermatol. 2012;66:241-51. https://doi.org/10.1016/j.jaad. 2010.12.005.

29. PIA InsightHealth: number of patients Cosentyx 1st line (data on file). 2019.

30. Huerta C, Rivero E, Rodríguez LAG. Incidence and risk factors for psoriasis in the general population. Arch Dermatol. 2007;143:1559-65. https://doi.org/10.1001/archderm.143.12. 1559.

31. Dossier zur Nutzenbewertung. Secukinumab (Cosentyx) Novartis Pharma GmbH, Modul 3 A, mittelschwere bis schwere PlaquePsoriasis. 2015.

32. Kimball AB, Yu AP, Signorovitch J, Xie J, Tsaneva M, Gupta SR, Bao Y, Mulani PM. The effects of adalimumab treatment and psoriasis severity on self-reported work productivity and activity impairment for patients with moderate to severe psoriasis. J Am Acad Dermatol. 2012;66:e67-76. https://doi.org/10.1016/j.jaad. 2010.10.020.

33. Institut für Arbeitsmarkt- und Berufsforschung (IAB): Sonderauswertung der IAB Arbeitszeitrechnung für WifOR. Arbeitszeit und Arbeitsvolumen nach Geschlecht und Altersgruppen (Inland, abgestimmt auf VGR-Eckwerte). 2017.

34. Statistisches Bundesamt (Destatis): Volkswirtschaftliche Gesamtrechnungen, Inlandsproduktberechnung, detaillierte Jahresergebnisse 2017, Fachserie 18 Reihe 1.4. Statistisches Bundesamt (Destatis), Wiesbaden. 2018.

35. Hofmann, Sandra. Einfluss nicht-marktlicher Tätigkeiten auf den materiellen Wohlstand und die Einkommensverteilung in Deutschland. Peter Lang International Academic Publishers; 2015.

36. Leontief W. Interrelation of prices, output, savings and investment. A study in empirical application of the economic theory of general interdependence. Rev Econ Stat. 1937;19:109-32.

37. Statistisches Bundesamt (Destatis): Volkswirtschaftliche Gesamtrechnungen - Input-Output-Rechnung 2014-Fachserie 18 Reihe 2 (Revision 2014, Stand: August 2017). Statistisches Bundesamt (Destatis). 2018.
38. Miller RE, Blair PD. Input-output analysis: foundations and extensions. 2nd ed. Cambridge: Cambrige University Press; 2009.

39. Himmler S, Mueller M, Sherif B, Ostwald D. A case study applying a novel approach to estimate the social impact of a medical innovation - the use of secukinumab for psoriatic arthritis in Germany. Expert Rev Pharmacoecon Outcomes Res. 2019. https://doi. org/10.1080/14737167.2019.1644169.

40. Himmler S, Branner JC, Ostwald DA. The societal impact of a biologic treatment of ankylosing spondylitis: a case study based on secukinumab. J Comp Eff Res. 2021;10(2):143-55. https://doi. org/10.2217/cer-2020-0077.

41. Jungen D, Augustin M, Langenbruch A, Zander N, Reich K, Strömer K, Thaci D, Purwins S, Radtke M, Gutknecht M. Costof-illness of psoriasis - results of a German cross-sectional study. J Eur Acad Dermatol Venereol. 2018;32:174-80. https://doi.org/ $10.1111 /$ jdv. 14543 .

42. Mustonen A. Economic burden of psoriasis. 2015. https://www. utupub.fi/bitstream/handle/10024/113111/AnnalesD1182Mus tonen.pdf?sequence=2\&isAllowed=y. Accessed 14 May 2020.

43. Berger K, Ehlken B, Kugland B, Augustin M. Cost-of-illness in patients with moderate and severe chronic psoriasis vulgaris in Germany. Krankheitskosten bei Patienten mit mittelschwerer und schwerer chronischer Psoriasis vulgaris in Deutschland. J Dtsch Dermatol Ges. 2005;3:511-8. https://doi.org/10.1111/j.16100387.2005.05729.x.

44. Polistena B, Calzavara-Pinton P, Altomare G, Berardesca E, Girolomoni G, Martini P, Peserico A, Puglisi Guerra A, Spandonaro F, Vena Gino A, Chimenti S, Ayala F. The impact of biologic therapy in chronic plaque psoriasis from a societal perspective: an analysis based on Italian actual clinical practice. J Eur Acad Dermatol Venereol. 2015;29:2411-6. https://doi.org/10.1111/jdv. 13307.

45. Feldman SR, Tian H, Gilloteau I, Mollon P, Shu M. Economic burden of comorbidities in psoriasis patients in the United States: results from a retrospective U.S. database. BMC Health Serv Res. 2017;17(1):337. https://doi.org/10.1186/s12913-017-2278-0.

46. Mustonen A, Mattila K, Leino M, Koulu L, Tuominen R. Psoriasis causes significant economic burden to patients. Dermatol Ther. 2014;4(1):115-24. https://doi.org/10.1007/s13555-014-0053-2. 